\title{
Supplementary Material \\ A Burner Platform for the Investigation of Ozonolysis-Assisted Flame Speeds
}

\author{
Christopher B. Reuter ${ }^{*}$,\# and Timothy M. Ombrello \\ U.S. Air Force Research Laboratory, Aerospace Systems Directorate, \\ Wright-Patterson AFB, $\mathrm{OH} 45433$ \\ *Corresponding author email: christopher.reuter.ctr@nrl.navy.mil \\ ${ }^{\#}$ Current address: U.S. Naval Research Laboratory, Chemistry Division, \\ 4555 Overlook Avenue SW, Washington, DC 20375
}




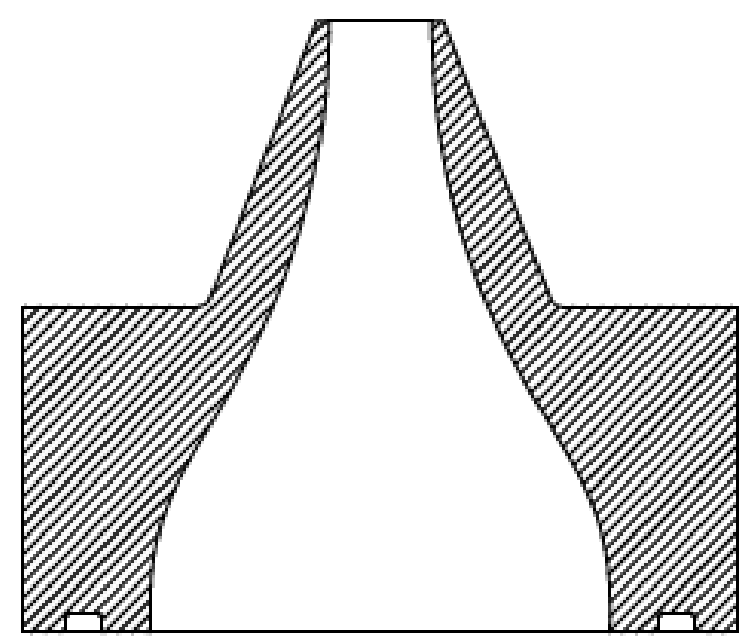

Figure S1. Cross-section of the contoured nozzle. For reference, the inner diameter at the exit is $6.35 \mathrm{~mm}$.
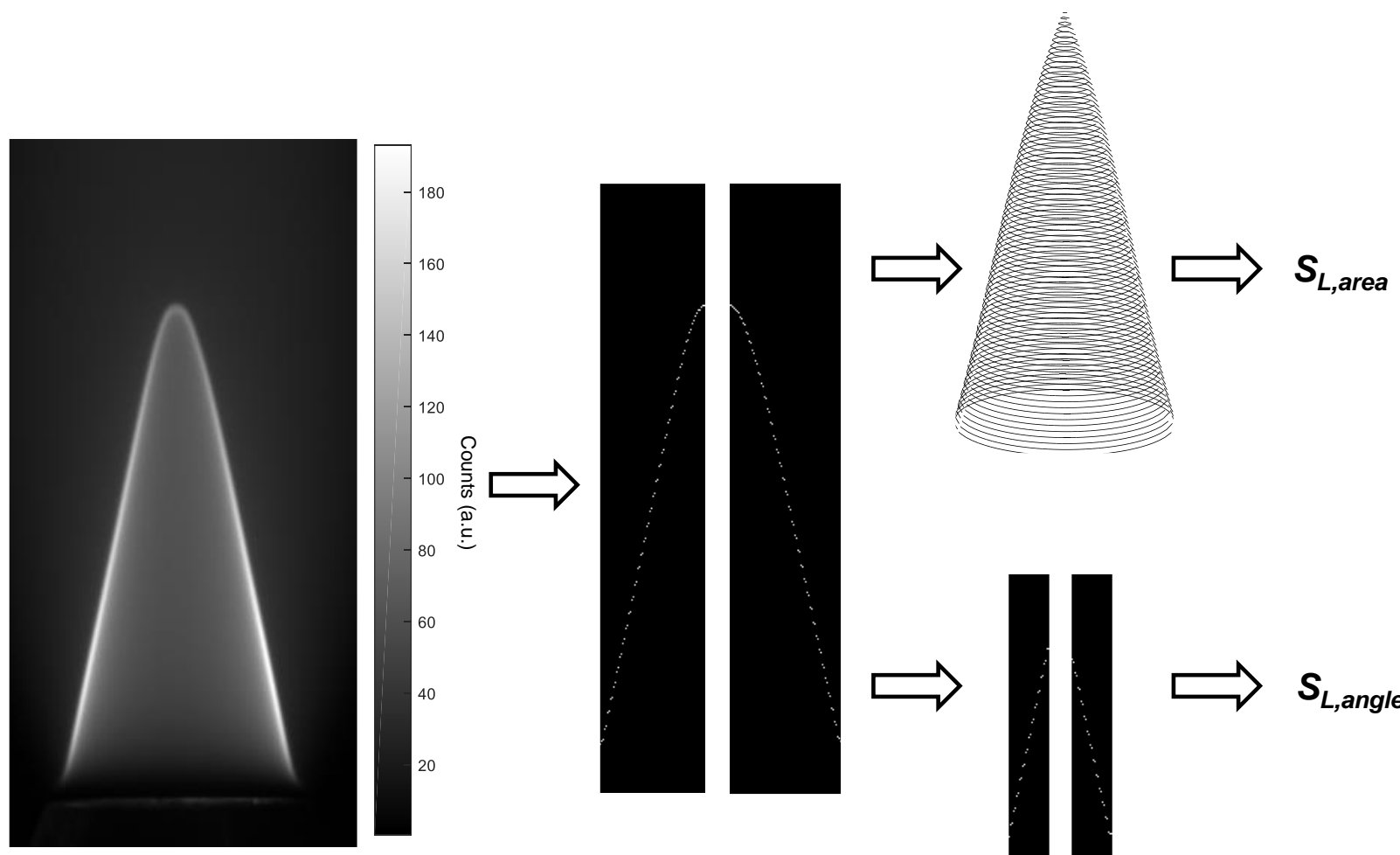

Figure S2. Image processing scheme for converting raw Bunsen flame images into measurements of flame speed. 


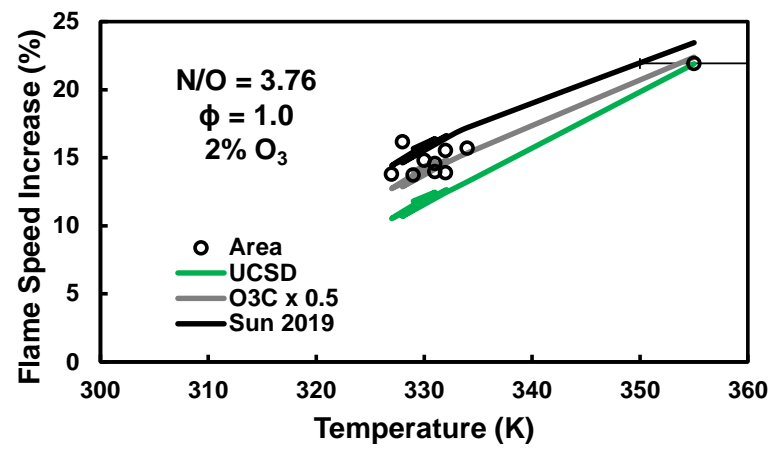

Figure S3. Predicted flame speed enhancement by $2 \% \mathrm{O}_{3}$ addition using three different ozonolysis submechanisms.

"UCSD" is the UCSD-based model with the Rousso et al. ozonolysis submechanism from the main paper. "O3C x 0.5 " multiplies the rate constants of the four ozonolysis reactions in the Rousso et al. submechanism by 0.5 . "Sun 2019" substitutes the four ozonolysis reactions from Sun et al. for the Rousso et al. submechanism. The slower ozonolysis reaction rates predict higher flame speed enhancement since less $\mathrm{O}_{3}$ is consumed within the flow reactor for a given measured temperature.

A.C. Rousso, N. Hansen, A.W. Jasper, Y. Ju, Low-temperature oxidation of ethylene by ozone in a jet-stirred reactor, The Journal of Physical Chemistry A 122 (2018) 8674-8685.

W. Sun, X. Gao, B. Wu, T. Ombrello, The effect of ozone addition on combustion: Kinetics and dynamics, Progress in Energy and Combustion Science 73 (2019) 1-25.

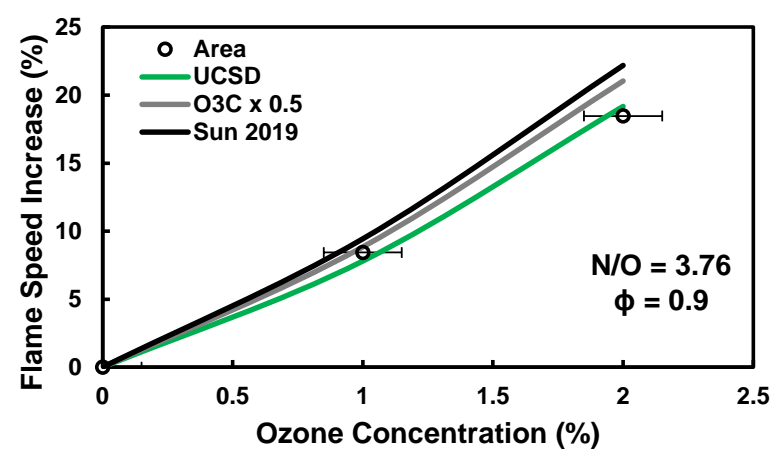

Figure S4. Predicted flame speed enhancement by $2 \% \mathrm{O}_{3}$ addition using three different ozonolysis submechanisms for an equivalence ratio of 0.9. 


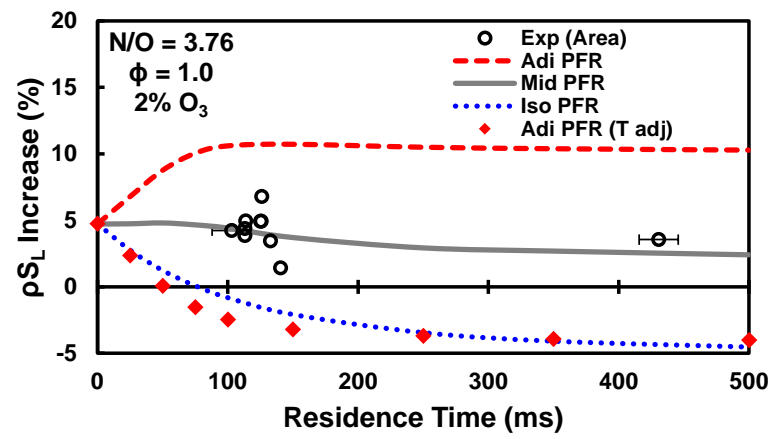

Supp. Fig. 5. Enhancement of mass burning rate by $\mathrm{O}_{3}$ as a function of residence time, showing experimental measurements and predictions (UCSD model) using different flow reactor boundary conditions.

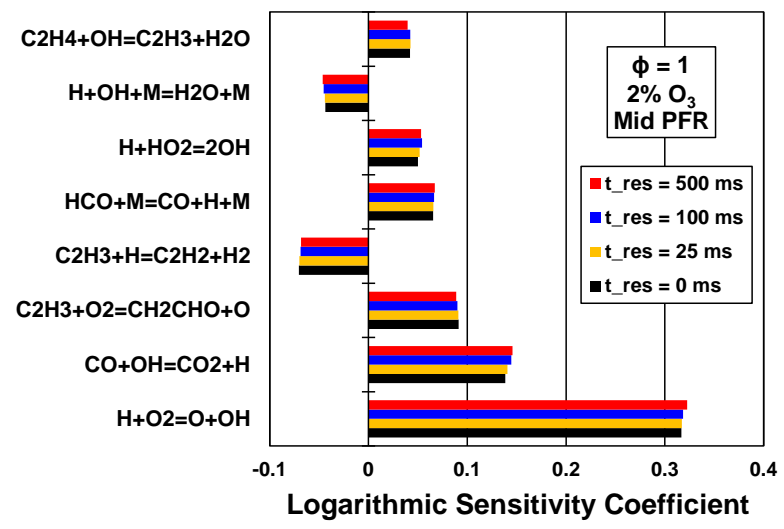

Figure S6. List of the most sensitive reactions for the flame speed of stoichiometric ethylene/air flames with $2 \% \mathrm{O}_{3}$ addition at four different plug flow reactor residence times under the midway PFR condition. Note that the sensitivity coefficients are computed using the FreeFlame module only (and not the FlowReactor + FreeFlame modules).

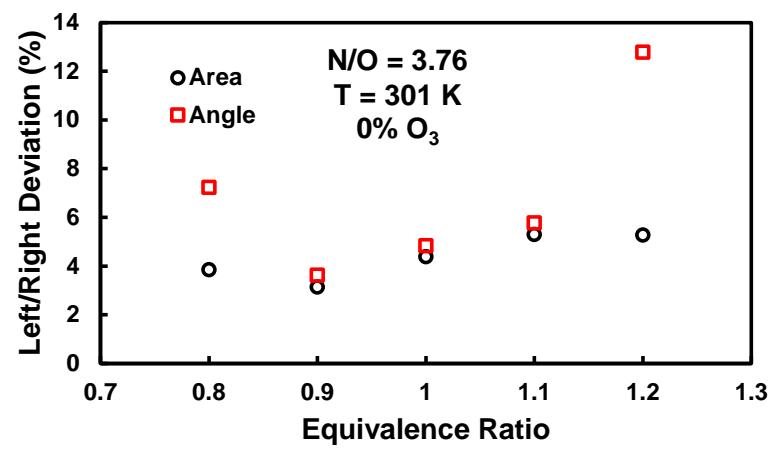

Figure S7. Asymmetry (deviation in flame speed) between left and right sides as a function of equivalence ratio for both the Bunsen area and Bunsen angle methods. 

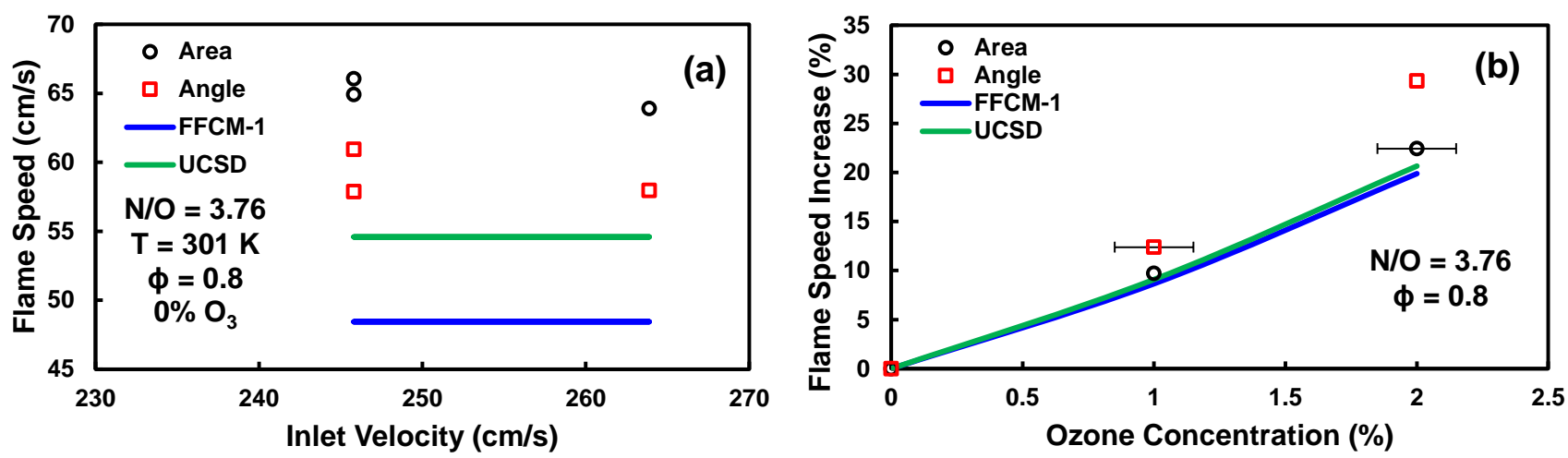

Fig. S8. Measurements and predictions of (a) flame speed without $\mathrm{O}_{3}$ and (b) enhancement of flame speed by $\mathrm{O}_{3}$ addition for $\phi=0.8$.
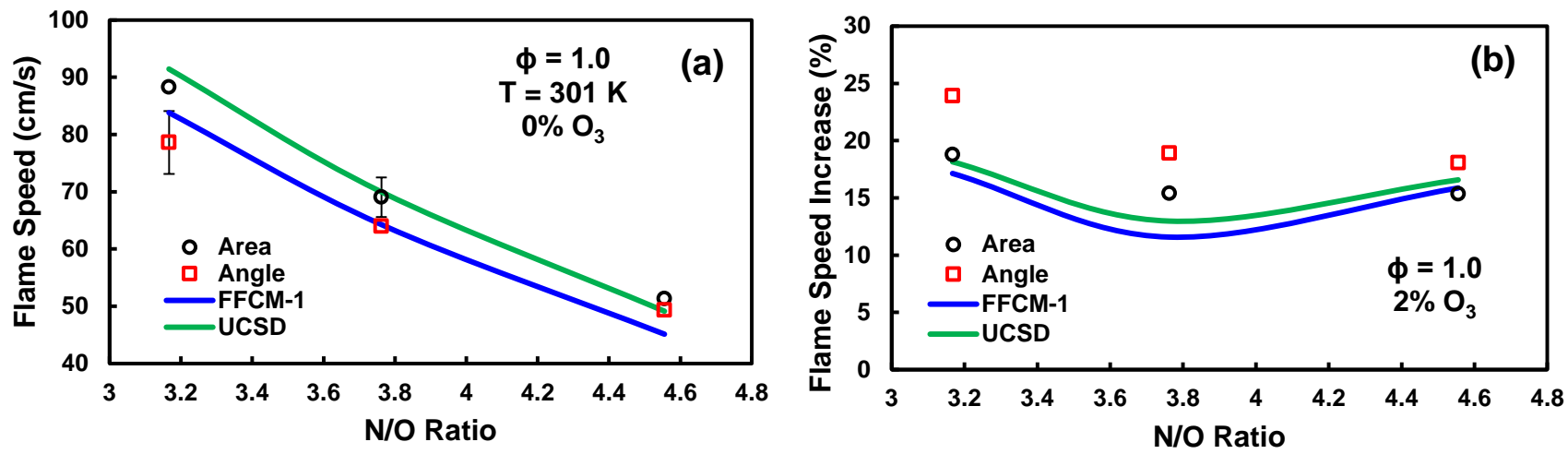

Fig. S9. Measurements and predictions of (a) flame speed without $\mathrm{O}_{3}$ and (b) enhancement of flame speed by $2 \% \mathrm{O}_{3}$ addition as a function of nitrogen/oxygen ratio. 